\title{
Coupling daily transpiration modelling with forest management in a semiarid pine plantation
}

\author{
Tarcísio JG Fernandes ${ }^{(1-2)}$, \\ Antonio D Del Campo ${ }^{(1)}$, \\ Rafael García-Bartual (1), \\ María González-Sanchis ${ }^{(1)}$
}

\begin{abstract}
Estimating forest transpiration is of great importance for Adaptive Forest $\mathrm{Ma}$ nagement (AFM) in the scope of climate change prediction. AFM in the Mediterranean region usually generates a mosaic of different canopy covers within the same forest. Several models and methods are available to estimate forest transpiration, but most require a homogeneous forest cover, or an individual calibration/validation process for each cover stand. Hence, a model capable of reproducing accurately the transpiration of the whole canopy-cover mosaic is necessary. In this paper, the use of Artificial Neural Network (ANN) is proposed as a flexible tool for estimating forest transpiration using the forest cover as an input variable. To that end, sap flow, soil water content and other environmental variables were experimentally collected under five Aleppo pine stands of different canopy covers for two years. These sets of inputs were then used for the ANN training. Stand transpiration was accurately estimated using climate data, soil water content and forest cover through the ANN approach (correlation coefficient $R=0.95$; Nash-Sutcliffe coefficient $E=0.90$; root-meansquare error RMSE $=0.078 \mathrm{~mm}$ day $^{-1}$ ). Finally, the input value for soil water content (when not available) was computed using the process-based model Gotilwa+. Then, this computed soil water content was used as input in the proposed ANN. This combination predicted the forest transpiration with values of $\mathrm{R}=0.90, \mathrm{E}=0.63$, and $\mathrm{RMSE}=0.068 \mathrm{~mm} \mathrm{day}^{-1}$. Artificial Neural Network proved to be a useful and flexible tool to predict the transpiration dynamics of an Aleppo pine stand regardless of the heterogeneity of the forest cover produced by adaptive forest management.
\end{abstract}

Keywords: Adaptive Forest Management, Artificial Neural Network (ANN), Forest Water-use, Pinus halepensis Mill. global change (Asbjornsen et al. 2011, Fitzgerald et al. 2013, Ungar et al. 2013). This is particularly important in Mediterranean ecosystems, which are extremely vulnerable to global climate change (IPCC 2007, Lindner et al. 2010, Vargas-Amelin \& Pindado 2013).

Adaptive forest management (AFM) in Mediterranean ecosystems seeks to couple the concept of ecophysiology with the dryland forests management techniques, through the development of an ecosystemlevel water balance (Ungar et al. 2013). In the Mediterranean Spain, AFM may im-
(1) Research Institute of Water and Environmental Engineering, Research Group in Forest Science and Technology (Re-ForeST), Universitat Politècnica de València, Camí de Vera $\mathrm{s} / \mathrm{n}$, E-46022 Valencia (Spain); (2) Centre of Biological sciences and Nature, Federal University of Acre, Rodovia BR-364, Km 04, Rio Branco, 69915-900 Acre (Brazil)

@ Tarcísio JG Fernandes (tjgfernandes@yahoo.com.br)

Received: Mar 17, 2014 - Accepted: Mar 25, 2015

Citation: Fernandes TJG, Del Campo AD, García-Bartual R, González-Sanchis M (2015). Coupling daily transpiration modelling with forest management in a semiarid pine plantation. iForest 9: 38-48. - doi: 10.3832/ifor1290-008 [online 2015-08-06]

Communicated by: Francesco Ripullone prove stand resilience and the balance between green (ecosystem needs) and blue (available for human use) water budgets (Falkenmark 2003) in Pinus halepensis Mill. (Aleppo pine) reforestations (Del Campo et al. 2014), which occupy over $5 \times 10^{5}$ ha of the region (Birot \& Gracia 2011). Thus, prediction of forest transpiration under different forest management scenarios represents a key factor for successful and appropriate AFM design in Mediterranean Spain.

Modeling the factors that influence transpiration is quite complex due to the existence of non-linear and complex interactions (Asbjornsen et al. 2011). The fundamental controls are the available water in the soil, the ability of plants to transfer water from the soil to leaves and the capacity of the atmosphere to absorb the transpired water (Davie 2008).

Forest transpiration may be estimated using different approaches. Dekker et al. (2000) reported that by considering all different types of process-orientated forest transpiration models, four different perspectives can be deduced: cooling of leaves, assimilation of $\mathrm{CO}_{2}$, energy balance and water balance. All of these perspectives show a wide variation in physiological details. However, the most widely used transpiration models are based on the 
energy balance, which are mostly derived from the Penman-Monteith's equation. They generally constitute the Process $\mathrm{Ba}$ sed Models (PBM). Nevertheless, these approaches are Big-Leaf models, whose application requires the assumption of a homogeneous forest cover or an individual calibration/validation process for each stand. Since the application of AFM usually leads to a mosaic of different forest cover and structures within the same forest, it is paramount to use of a method capable of including such heterogeneity.

Artificial Neural Network (ANN) techniques represent an attractive modeling approach to deal with this issue, as forest cover heterogeneity can easily be included as an input variable. ANN is a flexible mathematical structure, which is capable to identify complex nonlinear relationships between the input and output data sets. Furthermore, ANN models are considered useful and efficient, particularly when the characteristics of the processes are difficult to describe using physical equations (i.e., when the relationship between input and output variables is not explicit - Shirgure \& Rajput 2011). ANNs map the implicit relationship between inputs and outputs through training on field observations (Shirgure 2013). Furthermore, ANN usually achieves regression coefficient around 0.90, thus performing more accurately than other approaches such as statistical or PBM.

In recent years, ANNs have intensively been applied in forest and agriculture hydrology, e.g., in estimating evapotranspiration (Kumar et al. 2002, 2011, Adeloye et al. 2012, Huo et al. 2012), trunk sap flow (Liu et al. 2009) and transpiration (Zee 2001a, 2001b, Vrugt et al. 2002, Garcia-Santos 2007, 2011, Meijun et al. 2007, Li et al. 2009). In forest management, ANNs have also been applied to estimate tree volume (Gorgens et al. 2009, Silva et al. 2009, Diamantopoulou \& Milios 2010, Özçelik et al. 2010, 2014, Yu \& Jia-Yin 2012), growth modeling (Castro et al. 2013), tree height (Binoti et al. 2013a), and to describe diameter distribution (Leite et al. 2011, Binoti et al. $2013 \mathrm{~b})$. However, none of these applications include forest management as an input variable, at least in the estimation of transpiration. The use of this variable would: (i) extend capabilities and use of ANN-based modeling; (ii) allow a more accurate determination and quantification of the influence of forest management practices on transpiration; (iii) increase the resilience of forests to new climate conditions. Despite the aforementioned advantages, ANN have some limitations, e.g., it cannot be applied when some of the required input data are not available to forest managers. Under such circumstances a combination of ANN and PBM can be a useful alternative. Although their sophistication theoretically allow to reproduce the complex dynamics of forest ecosystems in details, it makes also difficult their use and evaluation (Van Oijen et al. 2005). Hence, PBM could be used in some cases to feed ANN when the estimate of the required input data is not readily available.

In this study, we aimed to develop a reliable model to estimate transpiration in forest stands considering explicitly the influence of forest management as an input variable. More specifically, we intended: (i) to explore the relationships between measured forest transpiration and explicative environmental variables to define the most reliable empirical model (Linear Models and ANN-based approaches); (ii) to incorporate forest cover as a forest management-derived variable into the chosen modeling approach and to evaluate its predictive ability; (iii) to evaluate the model performance when soil moisture has to be derived from other modeling approaches (Gotilwa+).

\section{Material and methods}

Sap flow, soil water content and other environmental variables were recorded for two years in five Aleppo pine stands (see below) with different canopy covers. First, a Multiple Linear Regression (MLR) and a General Linear Model (GLM) using field data were developed and validated to analyze the performance of both models in predicting transpiration. Subsequently, an ANN modeling scheme was used to estimate the stand transpiration using climate data, soil water content and forest cover as input variables. When soil water content data was not available (only for medium intensity thinning stand), it was first computed using the process-based model Gotilwa+ and then used as an input value in the modeled ANN.

\section{Study site and data collection}

The study site is a public forest of 4682 ha located in the Ayora valley region $\left(39^{\circ} 5^{\prime} \mathrm{N}\right.$,

Tab. 1 - Characteristics of control and thinned plots. (DBH): diameter at breast height; $\left(\mathrm{H}_{98}\right)$ : plot thinned in 1998 (plots L, $\mathrm{M}$ and $\mathrm{H}$ were thinned in 2008). Adapted from Molina \& Del Campo (2012).

\begin{tabular}{lcccc}
\hline Thinning Treatment & $\begin{array}{c}\text { Forest Cover } \\
(\%)\end{array}$ & $\begin{array}{c}\text { Density } \\
\text { (trees ha }\end{array}$ & $\begin{array}{c}\text { DBH } \\
(\mathbf{c m})\end{array}$ & $\begin{array}{c}\text { Height } \\
(\mathbf{m})\end{array}$ \\
\hline Control (C) & 84 & 1489 & $17.8 \pm 5.1$ & 11.5 \\
Low intensity $(\mathrm{L})$ & 68 & 744 & $21.2 \pm 4.1$ & 12.2 \\
Medium intensity $(\mathrm{M})$ & 50 & 478 & $21.7 \pm 4.0$ & 11.3 \\
High intensity $(\mathrm{H})$ & 22 & 178 & $20.4 \pm 1.6$ & 12.2 \\
High intensity-1998 $\left(\mathrm{H}_{98}\right)$ & 41 & 155 & $25.2 \pm 5.0$ & 12.6 \\
\hline
\end{tabular}

$1^{\circ} 13^{\prime} \mathrm{W}, 943 \mathrm{~m}$ a.s.l.) in the Southwest of Valencia province (Spain). The climate is Mediterranean with an average total annual rainfall of $478 \mathrm{~mm}$ and a mean annual temperature of $13.7^{\circ} \mathrm{C}(1960-2010)$. Soils are Calcisols, derived from Triassic limestone (gravel and boulders) with high percentage of carbonates (26-38\%, $\mathrm{pH} 7.7-8.2)$ and sandy-silty loam texture. Part of the area (22\%) is covered by Pinus halepensis Mill. stands 50-60 years old, with high tree density (approx. 1500 trees ha-1) mainly due to low forest management. Detailed information about the study site is available elsewhere (Molina \& Del Campo 2012).

In 2008, an experimental thinning was performed in four $30 \times 30 \mathrm{~m}$ plots, reducing the forest cover from $84 \%$ (C: control plot) to $22 \%$ (H: high intensity plot), $50 \%$ (M: medium intensity plot) and 68\% (L: low intensity plot). In addition, a nearby area thinned in $1998\left(\mathrm{H}_{98}\right)$ with 41\% cover was included in this study and considered as the temporal evolution of the high intensity (H) treatment (Tab. 1). Overall, five distinct plots with different forest covers were considered in this work.

Forest cover was measured in each plot with a vertical densitometer (GRS, Arcata, CA, USA) with 50 readings per plot in a $4 \times$ $4 \mathrm{~m}$ grid. Hydrological (transpiration and soil moisture) and environmental variables ( $T$ : air temperature in ${ }^{\circ} \mathrm{C} ; \mathrm{Sr}$ : solar radiation in $\mathrm{MJ} \mathrm{m}^{-2}$ day $^{-1}$; Ppt: rainfall in $\mathrm{mm}$; $R H$ : relative humidity in \%; and $W s$ : wind speed in $\mathrm{m}$ $\mathrm{s}^{-1}$ ) were collected from June 2009 to March 2011 (Tab. 2). Measurements of Ppt, $T$, and $R H$ were carried out by a single sensor (HR/T sensor, Decagon Devices, Pullman, USA) placed $1 \mathrm{~m}$ above the ground and close to the treatment plot. Values were recorded and averaged every $30 \mathrm{mi}-$ nutes. Afterward, these data were used to obtain values for mean, maximum and minimum daily temperature and vapor pressure deficit (VPD - Allen et al. 1998).

Daily values for solar radiation and wind speed were obtained from the Almansa weather station, located near the study site. Transpiration was measured using sap flow sensors (HRM-30, ICT International Pty Ltd., Armidale, Australia - Burgess et al. 2001) in four trees per plot according to the diametric distribution of trees in the plot. In the conversion of the heat pulse velocity to sap flow velocity, raw values were corrected for probe misalignment (Burgess et al. 2001) and differences in thermal diffusivity and wounding by examining the samples under a light microscopy (Barret et al. 1995). Baseline correction in the obtained series was performed according to Buckley et al. (2012).

The accumulated daily values of sap flow (water transpired by the entire tree) were estimated considering a radial distribution of the sap flux velocity in the sapwood of each selected tree (Delzon et al. 2004). The sapwood area per tree was measured after extracting samples with an increment core $(5 \mathrm{~mm})$ and measuring to the nearest 0.01 
mm with a measuring table (LINTAB 6.0, Frank Rinn, Heidelberg, Germany) coupled with the TSAP-Win ${ }^{\otimes}$ software package (Rinn 2011). Total transpiration by the pine forest $\left(T r, \mathrm{~mm} \mathrm{day}^{-1}\right)$ per treatment was calculated by multiplying the daily transpiration $\left(L\right.$, day $^{-1}$ tree $\left.^{-1}\right)$ by the frequency of diameter class $(f)$ and the stand density (trees ha-1) by the following equation (eqn. 1):

$$
\operatorname{Tr}=\frac{\sum\left(\operatorname{Tr}_{n} \cdot f_{n}\right) \cdot N}{10000}
$$

where $T r_{\mathrm{n}}$ is the daily transpiration of each treatment $\left(\mathrm{mm} \mathrm{day}^{-1}\right), f_{\mathrm{n}}$ is the frequency of each tree class measured, $N$ is the number of trees in the stand (Tab. 1), and the denominator 10000 is for conversion of litters ha ${ }^{-1}$ into $\mathrm{mm}$.

Soil water content $\left(S W C, \mathrm{~cm}^{3} \mathrm{~cm}^{-3}\right)$ was measured every 20 minutes by capacitance sensors (Echo, Decagon Devices Inc., Pullman, WA, USA) and averaged to a daily value. In each treatment, three sensors were placed under the crown-projected area at $30 \mathrm{~cm}$ depth beneath two randomly selected trees out of the four trees sampled for transpiration. The daily values of the sensors were individually calibrated, averaged and converted to obtain the daily value per treatment. Tab. 2 summarizes the different data collected in the present study.

The medium intensity treatment $(M)$ presented numerous data gaps for most variables (including transpiration and soil moisture). For this reason, $M$ was chosen to test the model performance with the derived variable $(S W C)$ generated by PBM (objective iii). Hence, this treatment was discarded for model building, evaluation and validation either with linear or ANN techniques.

\section{Transpiration modeling}

\section{Multiple Linear Regression (MLR) and General Linear Models (GLM)}

Artificial neural networks are widely considered as a powerful tool in the identification of highly non-linear systems, like the target variable in this study (daily transpiration). Nonetheless, a more traditional approach based on multiple linear regression (MLR) is also presented, providing an interesting modeling benchmark using appropriate final performance index (see below). Not only this classical, well known MLR approach was used, but also a linear regression was implemented through a simplified neural network with only two layers and linear nodes, which will be referred in the following as general linear model (GLM - Özesmi et al. 2006). These two models (MLR and GLM) represent an adequate benchmark to evaluate the relative merits and performance of the neural network approach (Özesmi et al. 2006, Liu et al. 2009). Both methods were individually applied to each treatment ( $\mathrm{C}, \mathrm{L}, \mathrm{H}$ and $\mathrm{H} 98$ ), as well

Tab. 2 - Mean values \pm standard deviation of the recorded variables in each treatment (years 2009-2011). (N): number of days available for analysis; $(T r)$ : Transpiration ( $\mathrm{mm}$ day $\left.^{-1}\right)$; $(S W C)$ : average daily soil water content $\left(\mathrm{cm}^{3} \mathrm{~cm}^{-3}\right) ;(P p t)$ : precipitation $(\mathrm{mm})$; $\left(T_{\max }, T_{\min }\right.$ and $\left.T\right)$ : maximum, minimum and mean temperature, respectively $\left({ }^{\circ} \mathrm{C}\right) ;(R H)$ : relative humidity; $(V P D)$ : vapour pressure deficit $(\mathrm{kPa}) ;(W s)$ : wind speed $\left(\mathrm{m} \mathrm{s}^{-1}\right) ;(S r)$ : solar radiation transformed in equivalent evaporation $\left(\mathrm{mm}^{-1} \mathrm{day}^{-1}\right)$. Solar radiation expressed in $\mathrm{MJ} \mathrm{m}^{-2}$ day ${ }^{-1}$ was converted to equivalent evaporation in $\mathrm{mm}^{-1 a y}$ as the inverse of the latent heat of vaporization $(1 / \mathrm{L}=0.408$ - Allen et al. 1998).

\begin{tabular}{llcccccc}
\hline Variable & $\begin{array}{l}\text { Thinning } \\
\text { intensity }\end{array}$ & $\mathbf{2 0 0 9}$ & $\mathbf{N}$ & $\mathbf{2 0 1 0}$ & $\mathbf{N}$ & $\mathbf{2 0 1 1}$ & $\mathbf{N}$ \\
\hline$T r$ & High & $0.44 \pm 0.26$ & 187 & $0.34 \pm 0.20$ & 309 & $0.14 \pm 0.10$ & 90 \\
& High-1998 & $0.29 \pm 0.15$ & 187 & $0.22 \pm 0.13$ & 128 & - & 90 \\
& Medium & - & - & $0.19 \pm 0.12$ & 99 & $0.13 \pm 0.09$ & 90 \\
& Low & $0.31 \pm 0.18$ & 187 & $0.38 \pm 0.26$ & 309 & $0.19 \pm 0.14$ & 90 \\
& Control & $0.32 \pm 0.26$ & 187 & $0.47 \pm 0.36$ & 309 & $0.25 \pm 0.19$ & 90 \\
$S W C$ & High & $0.19 \pm 0.06$ & 187 & $0.26 \pm 0.06$ & 309 & $0.28 \pm 0.02$ & 90 \\
& High-1998 & $0.11 \pm 0.04$ & 187 & $0.19 \pm 0.03$ & 128 & $0.20 \pm 0.03$ & 90 \\
& Low & $0.13 \pm 0.07$ & 187 & $0.19 \pm 0.06$ & 309 & $0.19 \pm 0.04$ & 90 \\
& Control & $0.15 \pm 0.07$ & 187 & $0.22 \pm 0.06$ & 309 & $0.22 \pm 0.03$ & 90 \\
$T_{\max }$ & - & $23.2 \pm 9.42$ & 187 & $20.1 \pm 8.94$ & 309 & $11.0 \pm 4.33$ & 90 \\
$T_{\min }$ & - & $11.2 \pm 6.08$ & 187 & $8.5 \pm 5.91$ & 309 & $2.3 \pm 3.43$ & 90 \\
$T$ & - & $16.9 \pm 7.52$ & 187 & $13.9 \pm 7.16$ & 309 & $6.1 \pm 3.22$ & 90 \\
$R H$ & - & $0.6 \pm 0.20$ & 187 & $0.7 \pm 0.15$ & 309 & $0.8 \pm 0.12$ & 90 \\
$V P D$ & - & $1.0 \pm 0.88$ & 187 & $0.7 \pm 0.59$ & 309 & $0.3 \pm 0.17$ & 90 \\
$P p t$ & - & $1.5 \pm 4.32$ & 187 & $1.8 \pm 4.67$ & 309 & $1.9 \pm 5.06$ & 90 \\
$W S$ & - & $2.3 \pm 1.32$ & 187 & $2.3 \pm 1.30$ & 309 & $2.4 \pm 1.53$ & 90 \\
$S r$ & - & $7.7 \pm 3.81$ & 187 & $7.2 \pm 3.35$ & 309 & $4.8 \pm 2.11$ & 90 \\
\hline
\end{tabular}

as to the data pooled together, including the forest cover as an input variable. In all cases, the target variable to be predicted was daily transpiration. Concerning input variables, a correlation analysis and a stepwise method was previously performed to assess variable selection process, which is common to both the approaches (MLR and GLM).

\section{Transpiration based on Artificial Neural Network}

Artificial neural network (ANN) modeling process comprises three stages: pre-processing (including variable selection, data division, data scaling and normalization), processing (ANN architecture and network training process) and post-processing or model evaluation (Gorgens et al. 2009). In each of the mentioned stages, the criteria listed in the next chapters were used.

\section{Stage 1: Data pre-processing}

A proper selection of relevant inputs for ANNs is important as they strongly influence the final performance of the model, particularly when interrelationships between predictor variables are known to occur.

The most relevant variables affecting the final transpiration rates are $V P D, S r, R H, T$, $W s, L A I$ (Liu et al. 2009), although the physical mechanisms involving groups and subgroups of variables acting simultaneously are complex non-linear processes. This fact makes the choice of optimal predictor variables difficult. For this purpose, a sensitivity analysis was conducted to avoid combinations of input variables that might yield an ill-conditioned system (Smith 2006). Different groups of input variables were tested in order to find the best combinations for improved transpiration rate predictions.

The first issue using an ANN modeling strategy is the division of the dataset into the training and the test subsets, as it can significantly affect the selection of optimal ANN structure and the evaluation of its forecasting performance (Zhang et al. 1998). A third data subset, usually named cross-validation set, is also used to avoid over-training problems or to determine the stopping point of the training process. Although no clear guidelines do exists for selecting the relative size of such subsets, we adopted the commonly used criterion of setting the size of the training set as $70 \%$ of the whole dataset, reserving the remaining data for the test (15\%) and cross-validation (15\%) sets.

Obviously, the use of representative subsets is of significant importance for the performance of the neural network and its final generalization capability. To account for it, transpiration data for each treatment were previously classified into four classes, with class limits set at $(\mu-\sigma), \mu$ and $(\mu+\sigma)$, where $\mu$ is the average value and $\sigma$ is the standard deviation. For each class, data were then classified considering the $V P D$ range and the different seasons separately. Finally, a $t$-test was applied to the training, test and cross validation sets to test for differences between sample means. No significant statistical differences between sample means $(p<0.05)$ were found.

The variables under consideration in this research span different ranges. In order to ensure that all variables receive equal attention during the ANN training process, the original data were transformed to the 
interval [0;1], with the exception of forest cover and $V P D$, according to the following equation (eqn. 2):

$$
x_{\text {norm }}=0.5 \cdot\left(\frac{x_{0}-\bar{x}}{x_{\max }-x_{\text {min }}}\right)+0.5
$$

where $x_{\text {norm }}$ is the normalized value, $x_{0}$ is the original value, $\bar{x}$ is the average value of the original series, and $x_{\max }$ and $x_{\min }$ are its maximum and minimum value, respectively.

In the case of forest cover, no transformation was required as original values already lie in the interval [0;1]. The second exception is $V P D$ variable. In neural network modeling, the probability distribution of input data does not need to be strictly known (Burke \& Ignizio 1992), although in some cases a skew reduction in the original data can be desirable, particularly when it is very significant. In present study, this was the case of the variable $V P D$, which was transformed with an exponential function (eqn. 3):

$$
x_{\text {norm }}=1-e^{-\bar{x} \cdot x_{0}}
$$

Obviously the direct output of the neural network (transpiration) is a scaled or normalized value, which needs to be converted to its original range before proceeding to the model performance evaluation procedure (Taylor \& Smith 2006).

\section{Stage 2: ANN architecture and training algorithm}

In this study a feed-forward artificial neural network (FFNN) is proposed as a mathematical model to predict forest transpiration rates. It consists of a set of sensory units that constitute the input layer, one or more hidden layers of computational nodes and an output layer of computational nodes producing the output of the network (Haykin 1994). Information passes only in one direction, from the input nodes to those in the succeeding layers up to the output layer. The strength of connections between nodes of successive layers is represented by the weight values, acting as parameters of the neural network model.

In general, the output layer has as many nodes as target variables. In our case, it will include only one node, corresponding to the sole target variable (daily transpiration). Concerning the number of hidden layers, no consolidated theory currently exists on the number of hidden layers needed for accurate predictions, although it has been proved that only one layer of hidden units with non-linear nodes is sufficient to approximate any function to an arbitrary level of precision (Hornik et al. 1989). Accordingly, a topology of three layers with a single output node in the third layer was designed. The number of nodes $i$ in the input layer is the number of predictor variables used.

A common problem in FFNN building is the specification of the number of nodes required in the hidden layer. It is worth to notice that the more complex is the mapping between the variables, the larger is the number of hidden nodes required. In this study, a range of neural networks were tested varying the number of hidden nodes from $i / 2$ to $2 i$, in order to select the optimal dimension of the network. In a similar way, a family of activation functions in the hidden and output layer were tested (logistic, hyperbolic tangent, and exponential for the hidden layer; exponential and identity function in the output node Vrugt et al. 2002, Meijun et al. 2007, Liu et al. 2009).

The training algorithm can be addressed as an unconstrained non-linear minimization problem in which weight values are iteratively modified to minimize the overall mean squared error between the desired and actual output values of scaled transpiration. A variety of powerful algorithms are reported in the literature, but in practice none of them guarantee the global optimal solution for a general nonlinear optimization problem, with efficiency and computational performance depending largely on the structure and characteristics of the unknown error function.

For most practical applications, the faster convergent and more efficient algorithms are the second-order methods, like the Broyden, Fletcher, Goldfarb and Shanno (BFGS), Levenberg-Marquardt and conjugate gradient (Zhang et al. 1998), although first-order method algorithms have also been successfully used in many relevant applications. Therefore, some popular methods were initially tested in our network, including the well-known standard backpropagation algorithm with variable learning rate (Kumar et al. 2002), the resilient backpropagation (Riedmiller \& Braun 1993, Igel \& Hüsken 2003), and the backpropagation algorithm with weight decay (Bergmeir \& Benitez 2012). However, in our case BFGS algorithm provided apparently better performance, showing faster training and superior generalization abilities of the resulting networks (Vojislav 2001, Igel \& Hüsken 2003, Nawi et al. 2006, Jing-Hua et al. 2010). This powerful technique is particularly suitable when a large number of topologies and activation functions are to be tested, as it was the case in this study. To avoid weights with high values in the selected networks, a regularization weight decay procedure was incorporated in the training process (Bishop 1995), that essentially consists of an addition of a term to the error function, penalizing the solutions with large weight values.

\section{Stage 3: Model evaluation}

The accuracy of predictions of the observed transpiration values can be measured using a variety of metrics, thus assessing the performance of the different models tested. Common statistics were computed, including R, E and RMSE (see below), no matter the type of model under examination.

\section{Process-based model}

In this study, the PBM GOTILWA+ was applied to estimate $S W C$, a variable that might not be readily available to forest managers. GOTILWA+ is an improved version of GOTILWA described by Gracia et al. (1999) and Kramer (2001). It can estimate accurately the water flux of Mediterranean forest ecosystems (different single-tree species stands: coniferous or broadleaved, evergreen or deciduous) under changing environmental conditions, due to either climate or forest management. For this reason, GOTILWA + was used here to estimate both transpiration (directly) and soil water content (to fed the ANN).

This model requires a number of inputs to simulate forest growth parameters at a daily time scale. The inputs describe the forest structure and physiology, soil and climate conditions. The forest structure was considered heterogeneous in terms of diametrical distribution, which was defined according to the initial tree inventory. Leaf photosynthesis and stomata conductance parameters for Pinus halepensis were included in the GOTILWA+ model based on measured data from experimental plots in Collserola (Catalonia - data available at http://www.creaf.uab.es/gotilwa+/SParame ters.htm). Soil parameters were obtained from an earlier study (Del Campo et al. 2008). Daily climatic data were obtained as previously described. GOTILWA+ performance was analyzed comparing the measured and estimated transpiration with soil moisture values, considering the index of model evaluation (see below).

\section{Model evaluation}

For comparisons between the measured and simulated transpiration using the ANN model, the multiple-linear regression (MLR), the general linear models (GLM) and GOTILWA+, three indexes were used: (i) the coefficient of correlation (R, eqn. 4); (ii) the Nash-Sutcliffe Efficiency (E, eqn. 5), which compares the performance of the model to a model that only uses the mean of the observed data ( 1 = perfect model; 0 = performance no better than simply using the mean; negative values = bad performance - Bennett et al. 2013); and (iii) the root mean squared error (RMSE, eqn. 6), which measures the deviation of model predictions from the observed data (Whitley et al. 2012 - eqn. 4, eqn. 5, eqn. 6):

$$
\begin{gathered}
R=\frac{\sum_{i=1}^{n}\left(Y_{o b s_{i}}-\bar{Y}_{o b s}\right)\left(Y_{s i m_{i}}-\bar{Y}_{s i m}\right)}{\sqrt{\sum_{i=1}^{n}\left(Y_{o b s_{i}}-\bar{Y}_{o b s}\right)^{2} \cdot \sqrt{\sum_{i=1}^{n}\left(Y_{s i m_{i}}-\bar{Y}_{s i m}\right)^{2}}}} \\
E=1-\frac{\sum_{i=1}^{n}\left(Y_{s i m_{i}}-Y_{o b s_{i}}\right)^{2}}{\sum_{i=1}^{n}\left(Y_{o b s_{i}}-\bar{Y}_{o b s}\right)^{2}} \\
R M S E=\sqrt{\frac{\sum_{i=1}^{n}\left(Y_{o b s_{i}}-Y_{s i m_{i}}\right)^{2}}{n}}
\end{gathered}
$$


where $n$ is the number of data considered, $Y_{\text {obs_ }}$ is the daily transpiration observed by heat pulse method for the $i$-th value, $Y_{\text {sim } i}$ is the simulated transpiration for the $i$-th value, $Y_{\text {obs }}$ and $Y_{\text {sim }}$ are the average values of corresponding variables, respectively. In addition, a graphical analysis was used to compare and verify presence of heteroscedasticity in the dataset.

\section{Results}

\section{Linear analysis}

The linear correlation matrix between input variables and daily transpiration showed that correlations differ significantly among the different treatments (plots) considered in this study (Tab. 3). Correlation values tend to be higher for intensive thinning, and lowest for the control treatment. It should be noted that in the case of strongly physically interrelated variables (i.e., VPD and transpiration), expected high values can be as low as 0.29 for the control treatment. Other variables, such as wind speed, precipitation and soil water content, showed negative, modest correlations in both individual treatments and grouped data. Based on these results, it follows that some variables do not significantly contribute to explain transpiration (e.g., Ws, which was not further considered). On the other hand, the co-linearity between variables made advisable to consider only those showing the highest correlations (as in the case of $R H$ with $P p t$ ).

Linear based models (MLR and GLM)
Tab. 3 - Linear correlation matrix between input variables and daily transpiration (mm) in each treatment. ( $T_{\max }, T_{\min }$ and $\left.T\right)$ : maximum, minimum and mean temperature, respectively $\left({ }^{\circ} \mathrm{C}\right) ;(R H)$ : relative humidity; $(V P D)$ : vapour pressure deficit $(\mathrm{kPa})$; $(P p t)$ : precipitation $(\mathrm{mm}) ;(W s)$ : wind speed $\left(\mathrm{m} \mathrm{s}^{-1}\right) ;(S r)$ : solar radiation, transformed in equivalent evaporation ( $\mathrm{mm}$ day $\left.{ }^{-1}\right) ;(S W C)$ : average daily soil water content $\left(\mathrm{cm}^{3}\right.$ $\mathrm{cm}^{-3}$ ).

\begin{tabular}{lccccccccc}
\hline Treatment & $\boldsymbol{T}_{\max }$ & $\boldsymbol{T}_{\min }$ & $\boldsymbol{T}$ & $\boldsymbol{R H}$ & $\boldsymbol{V P D}$ & $\boldsymbol{P p t}$ & $\boldsymbol{W} \boldsymbol{s}$ & $\boldsymbol{S r}$ & $\boldsymbol{S W C}$ \\
\hline High intensity & 0.86 & 0.75 & 0.84 & -0.76 & 0.82 & -0.32 & -0.17 & 0.85 & -0.35 \\
High intensity-1998 & 0.82 & 0.69 & 0.79 & -0.75 & 0.73 & -0.47 & -0.27 & 0.76 & -0.31 \\
Low intensity & 0.58 & 0.45 & 0.55 & -0.53 & 0.46 & -0.28 & -0.16 & 0.64 & 0.03 \\
Control & 0.42 & 0.30 & 0.38 & -0.40 & 0.29 & -0.25 & -0.14 & 0.53 & 0.22 \\
All grouped & 0.59 & $\mathbf{0 . 4 7}$ & $\mathbf{0 . 5 6}$ & -0.53 & 0.49 & -0.29 & -0.16 & 0.63 & 0.02 \\
\hline
\end{tabular}

Tab. 4 - Goodness-of-fit statistics for Multiple Linear Regression (MLR) and General Linear Method (GLM). (R): correlation coefficient; (RMSE): root mean squared error; (E): Nash-Sutcliffe efficiency; $\left(T_{\max }, T_{\min }\right.$ and $\left.T\right)$ : maximum, minimum and mean temperature, respectively; $(R H)$ : relative humidity; $(V P D)$ : vapour pressure deficit; $(S r)$ : solar radiation; $(S W C)$ : soil water content; (Cover): forest cover.

\begin{tabular}{llcccl}
\hline Model & Treatment & R & RMSE & E & Inputs \\
\hline MLR & High intensity & 0.91 & 0.093 & 0.84 & $T_{\max }, T, S r, R H, S W C$ \\
& High intensity-1998 & 0.87 & 0.071 & 0.76 & $T_{\max }, T_{\min }, S r, R H, V P D, S W C$ \\
& Low intensity & 0.81 & 0.135 & 0.66 & $T_{\max }, T_{\min }, T, S r, R H, V P D, S W C$ \\
& Control & 0.79 & 0.194 & 0.63 & $T_{\max }, T, S r, R H, V P D, S W C$ \\
& All grouped & 0.77 & 0.161 & 0.59 & $T_{\max }, T, S r, R H, V P D, S W C$, Cover \\
GLM & High intensity & 0.91 & 0.093 & 0.84 & $T_{\max }, T_{\min }, T, S r, R H, V P D, S W C$ \\
& High intensity-1998 & 0.87 & 0.071 & 0.76 & $T_{\max }, T_{\min }, T, S r, R H, V P D, S W C$ \\
& Low intensity & 0.81 & 0.135 & 0.66 & $T_{\max }, T_{\min }, T, S r, R H, V P D, S W C$ \\
& Control & 0.79 & 0.193 & 0.63 & $T_{\max }, T_{\min }, T, S r, R H, V P D, S W C$ \\
& All grouped & 0.75 & 0.166 & 0.56 & $T_{\max }, T_{\min }, T, S r, R H, V P D, S W C$, Cover \\
\hline
\end{tabular}

were developed for transpiration estima- ten different models were formulated by tion, both for each individual treatment varying the input variables under consideand for the grouped treatments. In total, ration. For each model, R, RMSE and E va-

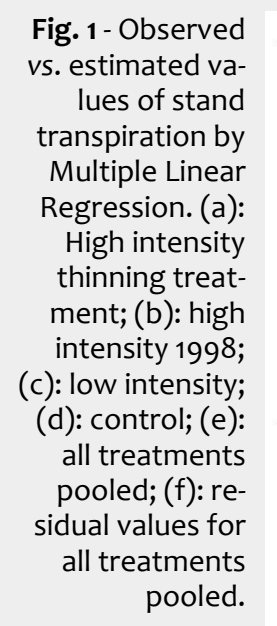

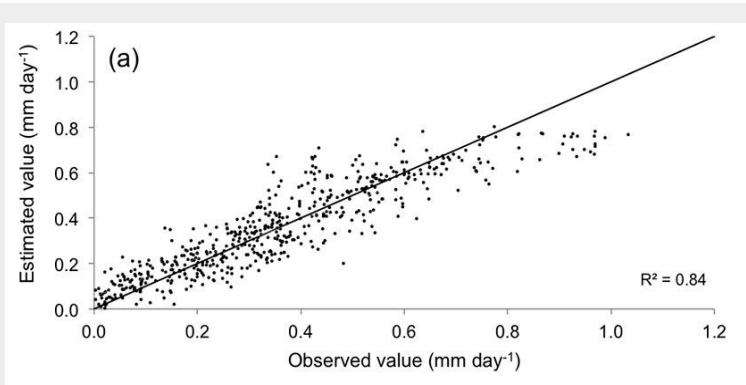
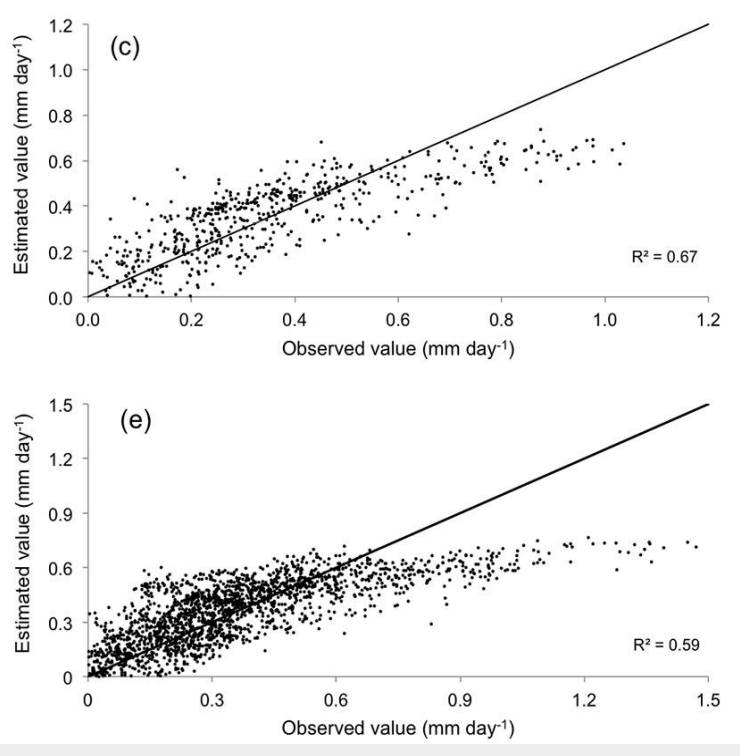
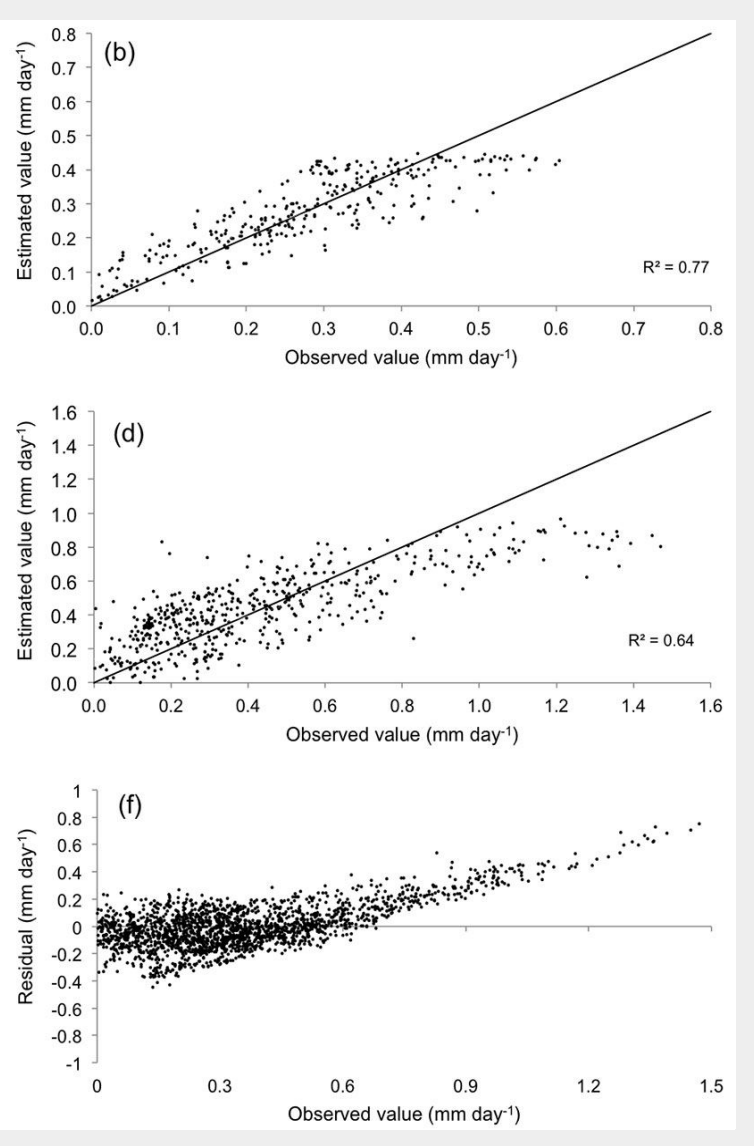
Tab. 5 - Comparison between measured and simulated transpiration for each treatment, using the selected Artificial Neural Network (8-9-1). Last row represents the ANN general performance. (R): correlation coefficient; (RMSE): root mean squared error; (E): Nash-Sutcliffe Efficiency; $\left(T_{\max }, T_{\min }\right.$ and $\left.T\right)$ : maximum, minimum and mean temperature, respectively; $(R H)$ : relative humidity; $(V P D)$ : vapour pressure deficit; $(S r)$ : solar radiation; $(S W C)$ : soil water content; (Cover): forest cover.

\begin{tabular}{lcccl}
\hline Treatment & $\mathbf{R}$ & RMSE & $\mathbf{E}$ & Inputs \\
\hline High intensity & 0.96 & 0.065 & 0.92 & \\
High intensity-1998 & 0.91 & 0.060 & 0.82 & $T_{\max }, T_{\min }, T, S r$, \\
Low intensity & 0.94 & 0.081 & 0.88 & $R H, V P D, S W C$, Cover \\
Control & 0.96 & 0.092 & 0.91 & \\
All grouped & 0.95 & 0.077 & 0.90 & \\
\hline
\end{tabular}

Tab. 6 - Average of observed (Obs) and estimated (Est) stand transpiration ( $\left.\mathrm{mm} \mathrm{day} \mathrm{y}^{-1}\right)$ using the Artificial Neural Network per season and treatment. Difference (in mm day ${ }^{-1}$ ) represents the average error per season and treatment.

\begin{tabular}{|c|c|c|c|c|c|c|c|c|c|c|}
\hline \multirow[t]{2}{*}{ Season } & \multirow[t]{2}{*}{$\mathbf{N}$} & \multicolumn{2}{|c|}{$\begin{array}{c}\text { High } \\
\text { intensity }\end{array}$} & \multicolumn{2}{|c|}{$\begin{array}{c}\text { High } \\
\text { intensity- } \\
1998\end{array}$} & \multicolumn{2}{|c|}{$\begin{array}{l}\text { Low } \\
\text { intensity }\end{array}$} & \multicolumn{2}{|c|}{ Control } & \multirow{2}{*}{ 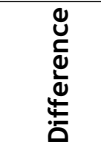 } \\
\hline & & Obs & Est & Obs & Est & Obs & Est & Obs & Est & \\
\hline Summer 2009 & 284 & 0.166 & 0.156 & 0.097 & 0.101 & 0.082 & 0.077 & 0.077 & 0.072 & 0.016 \\
\hline 009 & 352 & 0.089 & 0.084 & 0.069 & 0.057 & 0.086 & 0.080 & 0.095 & 0.085 & 0.034 \\
\hline $009-10$ & 180 & 0.029 & 0.022 & 0.021 & 0.020 & 0.031 & 0.026 & 0.034 & 0.031 & 0.015 \\
\hline Spring 2010 & 321 & 0.087 & 0.086 & 0.060 & 0.069 & 0.120 & 0.115 & 0.156 & 0.158 & -0.005 \\
\hline Summer 2010 & 300 & 0.164 & 0.169 & 0.028 & 0.027 & 0.174 & 0.168 & 0.202 & 0.209 & -0.005 \\
\hline Autc & 273 & 0.094 & 0.100 & - & - & 0.084 & 0.101 & 0.102 & 0.106 & -0.027 \\
\hline $10-11$ & 270 & 0.037 & 0.045 & - & - & 0.052 & 0.060 & 0.066 & 0.071 & -0.021 \\
\hline Spring 2011 & 93 & 0.051 & 0.057 & - & & 0.067 & 0.070 & 0.091 & 0.093 & -0.011 \\
\hline Difference & & -0.0 & & & & -0.0 & & -0.0 & & -0.0037 \\
\hline
\end{tabular}

lues were computed (Tab. 4), attaining fairly similar performances using both the MLR and GLM approaches. This was expected as both models comprise essentially a linear regression between inputs and output. On the other hand, the type of treatment was affecting significantly the prediction ability of the models, with $\mathrm{E}$ coefficient ranging from 0.63 to 0.84 (Tab. 4). Fig. 1 shows the estimated vs. observed values of transpiration obtained by MLR. Although results can reasonably be acceptable, a systematic underestimation was detected for larger values of transpiration, regardless the treatment considered (Fig. $1 a-d)$. The inclusion of an input variable related to forest management (forest cover) did not improve the model performances in either case (GLM nor MLR, All grouped Tab. 4). Conversely, such inclusion decreased both the Nash-Sutcliffe $(E<0.6)$ and the $\mathrm{R}$ coefficients, worsening the model's predictive ability at high transpiration values (Fig. 1e-f). However, the stepwise procedure of MLR showed better results than GLM on the pooled data (Tab. 4), although $T_{\text {min }}$ was used as input only in $\mathrm{H}_{98}$ and $\mathrm{L}$ treatments.

\section{Transpiration based on ANN}

A sensitivity analysis was conducted to identify the importance of different predictors used for estimating the forest transpiration. The error function showed the greatest increase when $S W C$ (soil moisture) was dropped out from the model, and thus it was considered as a key variable in the input family. The two subsequent variables that most affected the prediction error were $\mathrm{Sr}$ and $T_{\max }$. All the ANN models tested included these three variables, while all other predictors were included following a stepwise procedure. The best results were achieved when the input family included the variables $T_{\max }, T_{\min }, T_{\text {mean }}$, $S r, R H, V P D, S W C$ and Cover (Tab. 5). The optimal number of hidden nodes $\left(n_{\mathrm{h}}\right)$ for the best network performance was 9 , thus the network 8-9-1 was finally selected. Fig. 2 shows the values of $E$ and RMSE after training the networks with the different sizes of the hidden layer. Concerning the activation function, the best results were attained using a hyperbolic tangent function in the hidden nodes and an exponential function in the single node of the output layer.

Fig. 3 shows the relationship between the predicted and observed values of stand transpiration. Results were quite accurate, with $\mathrm{E}$ values ranging from 0.82 to 0.92 . Prediction accuracy did not significantly differ when the network with pooled data was considered (Fig. 3e) or when networks were used separately for each treatment (Fig. 3a-d). Tab. 6 shows the average error obtained in estimating the stand transpiration in different seasons. Significant differences in model performance were detected depending on the season, with the worst results obtained for autumn (Fig. 4). Finally, estimation errors were larger for high values of transpiration, as inferred from the residuals analysis (Fig. 3 f).

\section{Use of the PBM Gotilwa+}

Gotilwa+ predicted acceptable values of

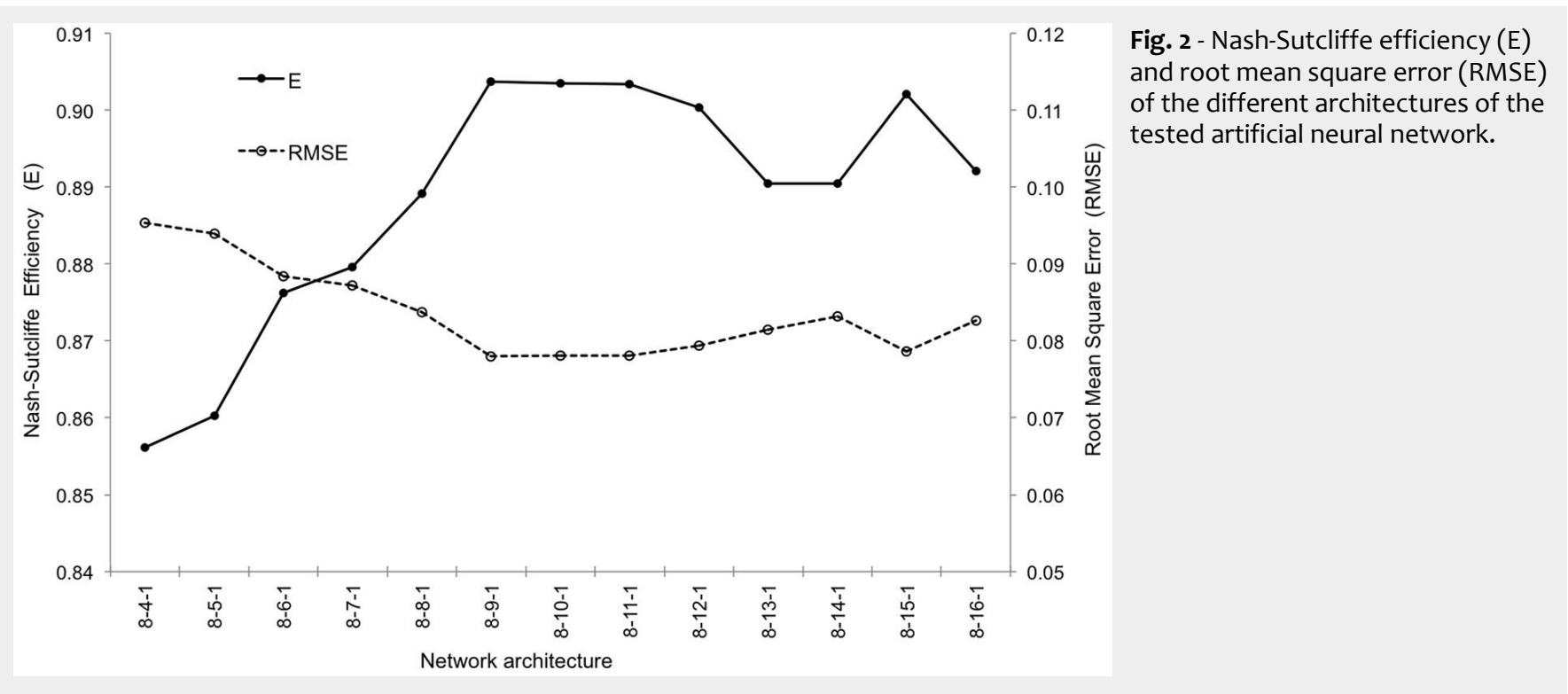




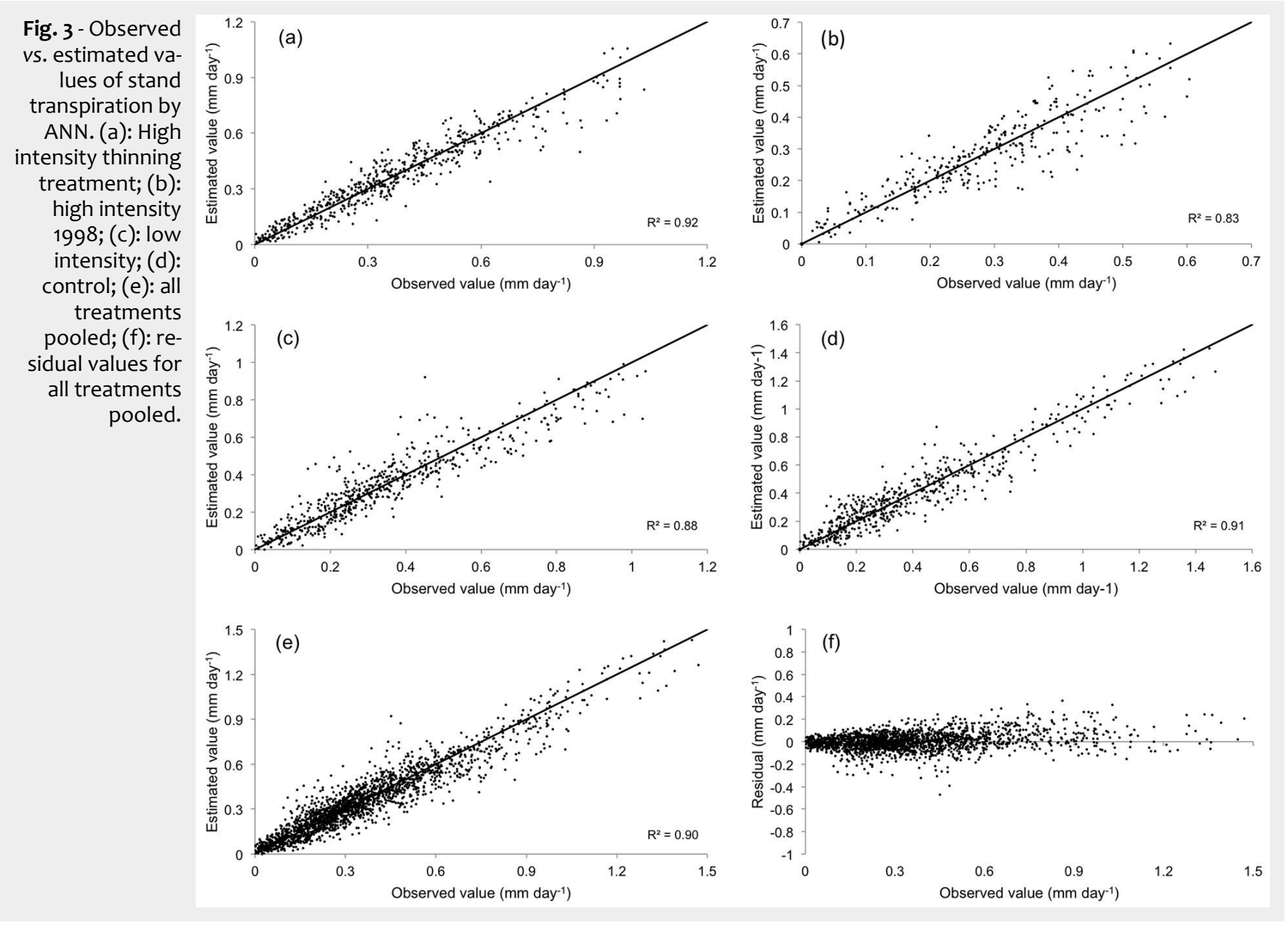

SWC (E from 0.47 to 0.68), though the estimated values for stand transpiration revealed a poor predictive ability of such model, except for the high intensity thinning treatment ( $E=0.57$ - Tab. 7). Comparing ANN and GOTILWA+ performances in terms of stand transpiration, the prediction accuracy achieved with the former model was higher than that obtained with the latter (Tab. 7). The performance of ANN-GOTILWA+ combination was validated comparing measured and estimated transpiration values of control, high, low and high 1998 thinning intensities (Tab. 7). Though the ANN-GOTILWA+ combination performed worse than ANN alone, predicted transpiration values were still accurate $(E$ ranging from 0.52 to 0.77 ), justifying its further use to estimate stand transpiration when $S W C$ data are not available. Therefore, these results support the use of PBM

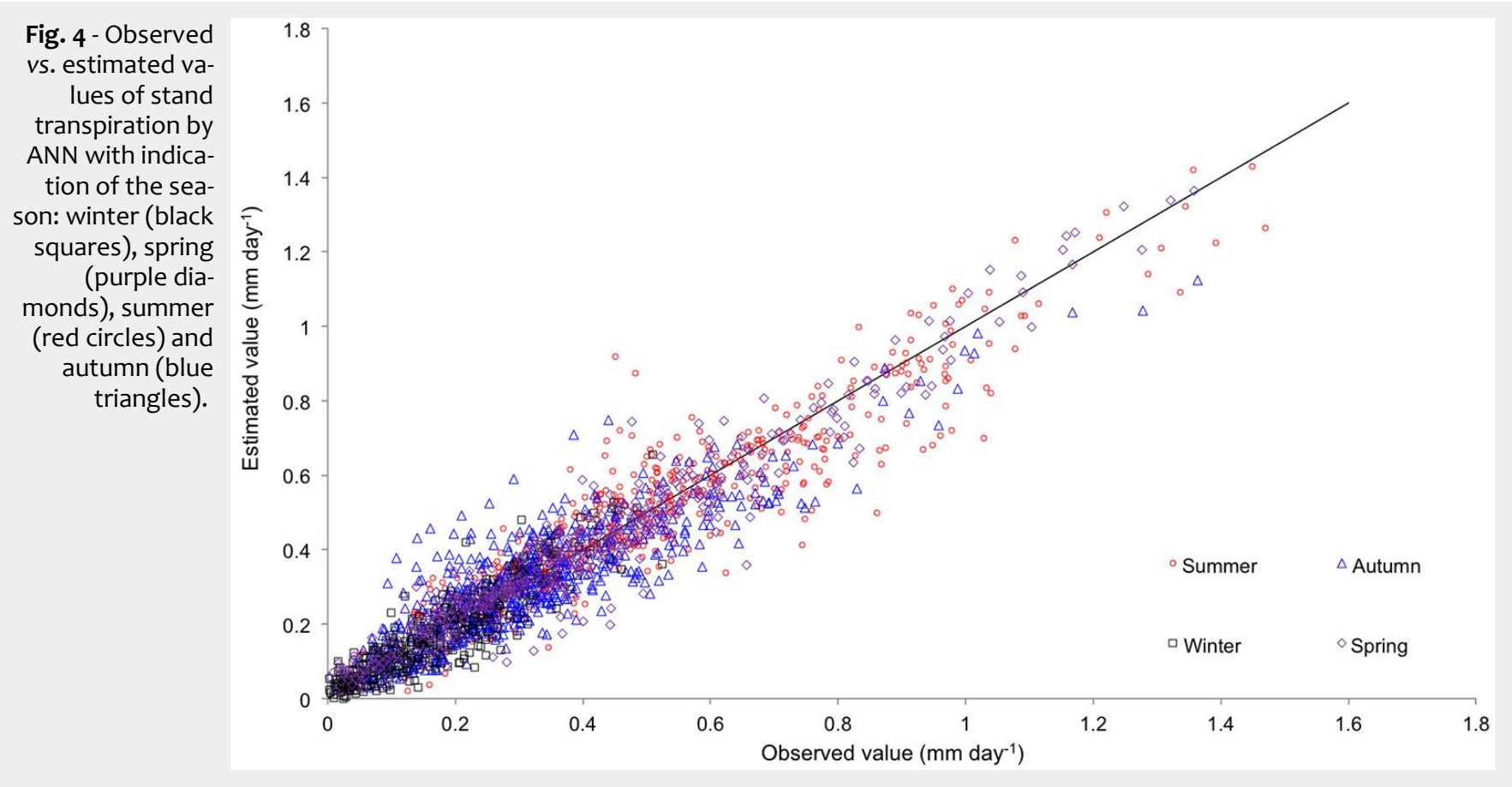


Tab. 7 - Comparison between observed and estimated Soil Water Content ( $S W C$ ) using Process-based Model (GOTILWA+). Observed and estimated transpiration ( $T r$ ) using GOTILWA+, the selected Artificial Neural Network (ANN), and the combination ANNGOTILWA+(SWC). (R): coefficient of correlation; (RMSE): Root Mean Squared Error; (E): Nash-Sutcliffe Efficiency.

\begin{tabular}{|c|c|c|c|c|c|}
\hline Treatment & Stats & $\begin{array}{c}S W C \\
\text { (GOTILWA+) }\end{array}$ & $\begin{array}{c}T r \\
\text { (GOTILWA+) }\end{array}$ & $\begin{array}{c}T r \\
\text { (ANN) }\end{array}$ & $\begin{array}{c}\boldsymbol{T r} \\
(\mathrm{ANN}+\mathrm{GOTILWA}+)\end{array}$ \\
\hline \multirow[t]{3}{*}{ High } & $\mathrm{R}$ & 0.8 & 0.8 & 0.96 & 0.95 \\
\hline & RMSE & 0.002 & 0.152 & 0.065 & 0.112 \\
\hline & E & 0.63 & 0.57 & 0.92 & 0.77 \\
\hline \multirow[t]{3}{*}{ High - 98} & $\mathrm{R}$ & 0.70 & 0.73 & 0.91 & 0.91 \\
\hline & RMSE & 0.037 & 0.130 & 0.060 & 0.082 \\
\hline & E & 0.47 & 0.19 & 0.82 & 0.68 \\
\hline \multirow[t]{3}{*}{ Low } & $\mathrm{R}$ & 0.86 & 0.68 & 0.94 & 0.9 \\
\hline & RMSE & 0.036 & 0.427 & 0.081 & 0.124 \\
\hline & E & 0.68 & -2.38 & 0.88 & 0.71 \\
\hline \multirow[t]{3}{*}{ Control } & $\mathrm{R}$ & 0.84 & 0.79 & 0.96 & 0.85 \\
\hline & RMSE & 0.039 & 0.463 & 0.092 & 0.220 \\
\hline & $\mathrm{E}$ & 0.64 & -1.11 & 0.91 & 0.52 \\
\hline \multirow[t]{3}{*}{ Medium } & $\mathrm{R}$ & & 0.87 & - & 0.90 \\
\hline & RMSE & - & 0.318 & - & 0.068 \\
\hline & $E$ & & -6.99 & - & 0.63 \\
\hline
\end{tabular}

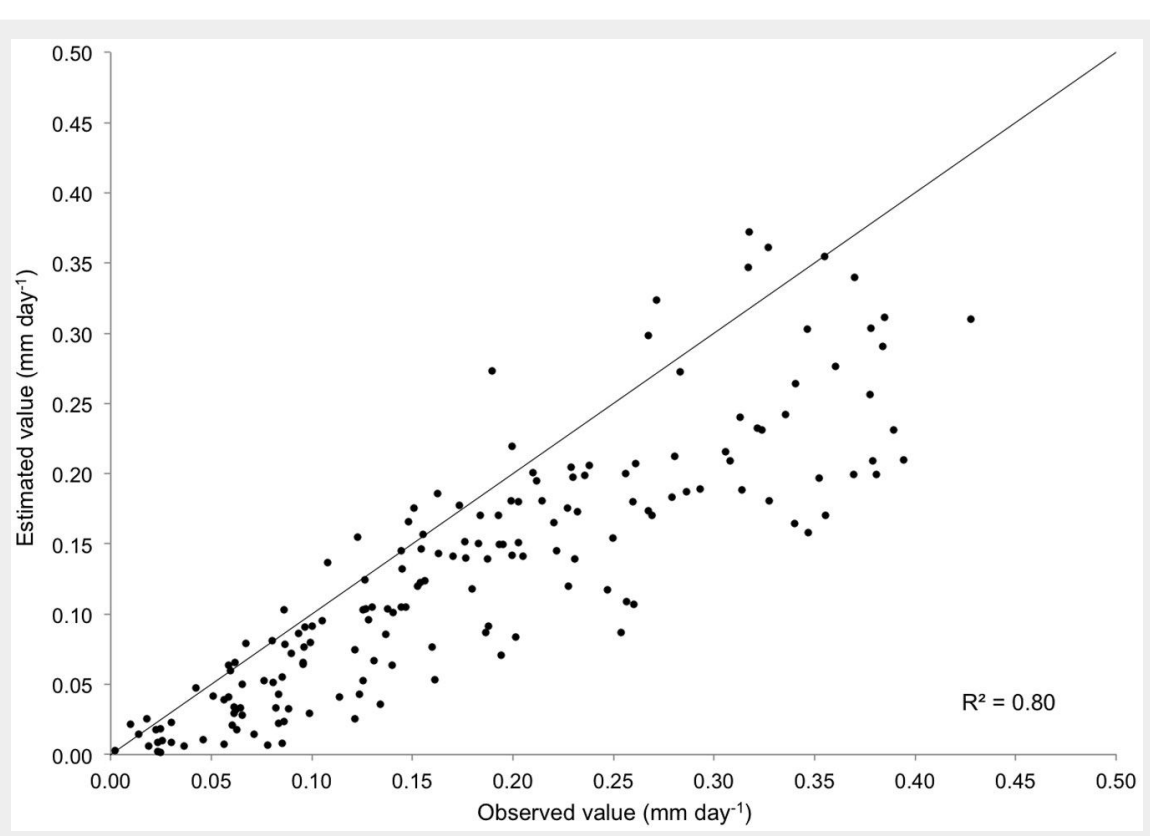

Fig. 5 - Observed vs. estimated values of stand transpiration in the medium intensity thinning treatment using the parameter soil water content $(S W C)$ generated by the software GOTILWA+.

to feed the ANN as a modeling strategy to estimate the stand transpiration when some of the ANN input data are not readily available. In this sense, ANN-GOTILWA+ was used to predict transpiration values of the medium thinning intensity treatment, where $S W C$ data were not available. The results showed that ANN-GOTILWA+ predicted accurately the stand transpiration, significantly increasing the $E$ value from -6.99 (Gotilwa+) to 0.63 (ANN-GOTILWA+ Fig. 5, Tab. 7).

\section{Discussion}

In this study, the influence of adaptative forest management (AFM) on different transpiration modeling approaches in a semiarid pine plantation has been con- sidered. Similarly to Asbjornsen et al. (2011), the application of a linear approach allowed to identify variables such as $S W C$, $T, S r, R H$ and $V P D$ as the inputs that mostly affect the forest transpiration. Such linear approach showed acceptable performance only for some of the treatments considered (Tab. 4). Other studies reported similar $R$ values when predicting transpiration with linear models (Lagergren \& Lindroth 2002, Liu et al. 2009, Ungar et al. 2013). However, we observed that model performance decreases as the forest cover increases (Tab. 4), probably due to the stand competition (canopy closure) as a primary determinant of transpiration over the environmental variables. The inclusion of the forest cover in the grouped linear model clearly worsened its performance. This indicates that even under identical site and climatic conditions, input variables for modeling stand transpiration may be different depending on forest cover, affecting the potential benefits of the model in operational forest management. The common strategy in these cases is the development of specific models in response to threshold behavior of environmental drivers (Lagergren \& Lindroth 2002, Mackay et al. 2012, Ungar et al. 2013), like soil moisture or forest cover. Such type of models are applicable only under the specific conditions where they were originally developed.

The artificial neural network modeling approach showed better performance than the two linear models applied (MLR and $G L M$ ) in predicting stand transpiration. In particular, neural network modeling showed an improved accuracy in predicting higher values of transpiration, giving high $\mathrm{E}$ values (>0.80 - Tab. 5). Nevertheless, prediction accuracy was not the same for all seasons. In particular, the performance of ANN for autumn was not as good as it was for the rest of the year. When larger prediction errors occurred, they could partially be explained by the variability of weather conditions along the day. However, this daily variability was not considered in our model, as only a single daily value was used for each variable. In any case, the relative average error in stand transpiration prediction was quite low, even in autumn $(<11 \%)$.

Previous studies have established a relationship between forest transpiration and season, and found differences in the performance of models depending on the season (Farrington et al. 1994, Borghetti et al. 1998, Schiller \& Cohen 1998, Cohen et al. 2008, Whitley et al. 2009, Chirino et al. 2011). Such a different behavior of transpiration is common in geographical regions with marked seasonal variations in the relationships between soil water availability, air temperature, vapor pressure deficit and rain distribution.

The structure of the neural network proposed here is a typical FFNN of three fully connected layers with standard configuration, with only one node in the output layer. Once the input variables are selected, the most relevant decision that determines the dimension or the geometry of the network is the number of hidden nodes $\left(n_{\mathrm{h}}\right)$ in the hidden or intermediate layer. Optimal network geometry is highly problem-dependent (Maier \& Dandy 2000). We applied a trial-and-error approach, i.e., training a number of different networks with different hidden layer sizes. Best performances were obtained for $n_{\mathrm{h}}=9$, which can be considered a "medium size" network performing adequately and adapted to the problem characteristics. Indeed, such structure has sufficient free weights to capture the essential relationships between variables, but at the same time not too many weights to produce over-fitting of the training data, thus affecting the ge- 
neralization ability of the network (Kumar et al. 2011). Several options were tested for the activation functions representing the individual node's internal operation. The hyperbolic tangent activation function chosen for the hidden nodes has been applied for similar problems, such as transpiration and trunk sap flow (Meijun et al. 2007, Liu et al. 2009), with satisfactory results. The most extended option for the output layer is that of linear activation functions (Vrugt et al. 2002, Garcia-Santos 2011), as it avoids directly the limitation of the range of possible output values. However, in our case the tests carried out with this option yielded a systematic underestimation of the higher values of transpiration. To overcome this problem, the exponential activation function in the output node has been used, producing better stand transpiration predictions, and reducing the observed tendency to underestimate the higher values.

The overall good performance shown by the selected neural network makes such modeling approach a promising tool with several practical implications in forestry. Indeed, the selected model is capable to estimate forest transpiration under different silvicultural treatments, using not only the common meteorological variables and soil water content as inputs, but also the forest cover. In other words, it can successfully be applied to estimate forest transpiration in a wide range of conditions, and can effectively incorporate diverse scenarios including climate change projections. As such, it constitutes a useful modeling support to forest managers for assessing the effect of different thinning intensities on forest transpiration.

GOTILWA+ reproduced accurately the soil water content, while transpiration was systematically underestimated. Some studies compared simulated and measured forest stand transpiration using GOTILWA+ (Kramer et al. 2002, Morales et al. 2005), but none used direct sap flow measurement in Aleppo pine stands. Kramer et al. (2002) reported a general systematic discrepancy between observed and predicted stand transpiration using GOTILWA+, with an underestimation particularly relevant at high radiation levels and low temperatures. In the same way, Morales et al. (2005) applied GOTILWA+ to estimate the actual evapotranspiration of different vegetation types, finding an actual evapotranspiration underestimated by $40-50 \%$. Despite the above discrepancy, the use of GOTILWA+ is still justified, at least in the case when the daily soil water content is not available as input data for ANN models.

\section{Conclusions}

In this study, the prediction of stand transpiration based on artificial neural networks gave promising results, to be considered a useful basis for future potential applications in water-oriented forestry and applied hydrology. ANN computational schemes has been successfully applied for the prediction of actual measured transpiration rates of forests from climatic data, soil water content and forest attributes. According to our results, ANN showed an improved capability of transpiration prediction as compared to other linear models. This outcome is consistent with the inherently non-linear relationships associated with the complex physical mechanisms underlying the transpiration process.

The use of prediction methods based on advanced mathematical tools like the ANN can effectively reduce the experimental field work to be held (e.g., sap-flow method) for assessing the stand transpiration, without significantly affecting the overall estimate of the expected transpiration rates, for a given area and a given forest treatment. Furthermore, silvicultural practices (represented in this work by the forest cover variation among treatments) are an input to the neural network, clearly extending the practical benefits of the method. In this sense, forest transpiration can be estimated under a wide range of conditions, for instance, a variety of managing scenarios or even climate change projections. From this perspective, the present approach represents a useful model strategy to provide recommendations for forest management in the light of the forest water use.

\section{Acknowledgements}

The authors are grateful to the Valencia Regional Government (CMAAUV, Generalitat Valenciana) and the VAERSA staff for allowing the use of the La Hunde experimental forest and for assistance in carrying out the fieldwork. The authors thank Rafael Herrera and Lelys Bravo de Guenni for their critical reviews of earlier versions of this manuscript. The authors thank Sabina Cerruto Ribeiro for improving the English language. The authors thank the reviewers for their contributions to improve the scientific quality of this paper. TJGF thanks the Mundus 17 program, coordinated by the University of Porto, Portugal.

This study is a part of research projects: "CGL2011-28776-C02-02, HYDROSIL", "CGL 2014-58127-C3-2, SILWAMED," funded by the Spanish Ministry of Science and Innovation and FEDER funds, and "Determination of hydrologic and forest recovery factors in Mediterranean forests and their social perception", led by Dr. Eduardo Rojas and supported by the Ministry of Environment, Rural and Marine Affairs (Spanish Government).

\section{References}

Adeloye AJ, Rustum R, Kariyama ID (2012). Neural computing modelling of the reference crop evapotranspiration. Environmental Modelling and Software 29: 61-73. - doi: 10.1016/j.envsoft. 2011.10.012

Allen RG, Pereira LS, Raes D, Smith M (1998). Crop evapotranspiration. Guide lines for computing crop evapotranspiration. FAO Irrigation and Drainage Paper 56, United Nations of Food and Agriculture Organization, Rome, Italy, pp. 15. [online] URL: http://appgeodb.nancy.inra.fr/ biljou/pdf/Allen_FAO1998.pdf

Asbjornsen $\mathrm{H}$, Goldsmith GR, Alvarado-Barrientos MS, Rebel K, Osch FPV, Rietkerk M, Chen J, Gotsch S, Tobón C, Geissert DR, Gómez-Tagle A, Vache K, Dawson TE (2011). Ecohydrological advances and applications in plant-water relations research: a review. Journal of Plant Ecology 4: 3-22. - doi: 10.1093/jpe/rtroo5

Barret D, Hatton T, Ash J, Ball M (1995). Evaluation of the heat pulse velocity technique for measurement of sap flow in rainforest and eucalyptus forest species of south-eastern Australia. Plant, Cell and Environmental 18: 463469. - doi: 10.1111/j.1365-3040.1995.tboo381.x

Bennett ND, Croke BFW, Guariso G, Guillaume JHA, Hamilton SH, Jakeman AJ, Marsili-Libelli S, Newham LTH, Norton JP, Perrin C, Pierce SA, Robson B, Seppelt R, Voinov AA, Fath BD, Andreassian V (2013). Characterising performance of environmental models. Environmental Modelling and Software 40: 1-20. - doi: 10.1016/j.envsoft.2012.09.011

Bergmeir C, Benitez JM (2012). Neural networks in R using the Stuttgart Neural Network Simulator: RSNNS. Journal of Statistical Software 46: 1-26. [online] URL: http://core.ac.uk/download/ pdf/27215258.pdf

Binoti MLMS, Binoti DHB, Leite HG (2013a). Aplicação de redes neurais artificiais para estimação da altura de povoamentos equianeos de eucalipto [Application of artificial neural networks to estimate the height of even-aged stands of eucalyptus]. Revista Árvore 37: 639645. [in Portuguese] - doi: 10.1590/S0100-6762 2013000400007

Binoti DHB, Binoti MLMS, Leite HG, Silva AALA, Albuquerque AC (2013b). Modelagem da distribuição de diametros utilizando autômatos celulares e redes neurais artificiais [An approach to diameter distribution modeling using cellular automata and artificial neural network]. Cerne 19: 677-685. [in Portuguese] - doi: 10.1590/S0104-77602013000400019

Birot Y, Gracia C (2011). The hydrologic cycle at a glance: blue and green water. In: "Water for forests and people in the Mediterranean region: a challenging balance. What Science Can Tell Us" (Birot Y, Gracia C, Palahi M eds). EFI, Joensuu, Finland, pp. 17-21.

Bishop CM (1995). Neural networks for pattern recognition. Clarendon Press, Oxford, UK, pp. 482. [online] URL: http://books.google.com/ books?id=ToSoBgAAQBAJ

Borghetti M, Cinnirella S, Magnani F, Saracino A (1998). Impact of long-term drought on xylem embolism and growth in Pinus halepensis Mill. Trees - Structure and Function 12: 187-195. - doi: 10.1007/PLoooog709

Buckley TN, Turnbull TL, Pfautsch S, Gharun M, Adams MA (2012). Differences in water use between mature and post-fire regrowth stands of subalpine Eucalyptus delegatensis R. Bker. Forest Ecology and Management 270: 1-10. doi: 10.1016/j.foreco.2012.01.008

Burgess SO, Adams MA, Turner NC, Beverly CR, Ong CK, Khan AH, Bleby TM (2001). An improved heat pulse method to measure low and reverse rates of sap flow in woody plants. Tree Physiology 21: 589-598. - doi: 10.1093/treephys/ 
21.9.589

Burke LI, Ignizio JP (1992). Neural networks and operations research: an overview. Computers and Operations Research 19: 179-189. - doi: 10.1016/0305-0548(92)90043-5

Castro RVO, Soares CPB, Leite HG, Souza AL, Nogueira GS, Martins FB (2013). Individual growth model for Eucalyptus stands in Brazil using artificial neural network. ISRN Forestry, Article ID 196832, pp. 1-12. - doi: 10.1155/2013/ 196832

Chirino E, Bellot J, Sánchez JR (2011). Daily sap flow rate as an indicator of drought avoidance mechanisms in five Mediterranean perennial species in semi-arid southeastern Spain. Trees Structure and Function 25: 593-606. - doi: 10.1007/s00468-010-0536-4

Cohen Y, Cohen S, Cantuarias-Aviles T, Schiller G (2008). Variations in the radial gradient of sap velocity in trunks of forest and fruit trees. Plant and Soil 305: 49-59. - doi: 10.1007/s11104-0079351-0

Davie T (2008). Fundamentals of hydrology ( $2^{\text {nd }}$ edn). Routledge Fundamentals of Physical Geography, London, UK, pp. 200. [online] URL: http://books.google.com/books?id=xoHfA6HJv ogC

Dekker SC, Bouten W, Verstraten JM (2000). Modelling forest transpiration from different perspectives. Hydrological Process 14: 251-260. doi: $10.1002 /(\mathrm{SICl}) 1099-1085(20000215) 14: 2<25$ 1::AID-HYP923>3.0.CO;2-R

Del Campo AD, Aguilella A, Lidón A, Segura G (2008). Influencia del tipo y dosis de hydrogel en las propriedades hidrofísicas de tres suelos forestales de distinta textura [Effects of dosage and type of hydrogel in the hydro-physical properties of three different textured soils]. Cuadernos de la Sociedad Española de Ciencias Forestales 25: 137-143. [in Spanish]

Del Campo AD, Fernandes TJG, Molina AJ (2014). Hydrology-oriented (adaptive) silviculture in a semiarid pine plantation: how much can be modified the water cycle through forest management? European Journal of Forest Research 133: 879-894. - doi: 10.1007/s10342-014-0805-7 Delzon S, Sartore M, Granier A, Loustau D (2004). Radial profiles of sap flow with increasing tree size in maritime pine. Tree Physiology 24: 1285-1293. - doi: 10.1093/treephys/24.11.1285 Diamantopoulou M, Milios E (2010). Modelling total volume of dominant pine trees in reforestations via multivariate analysis and artificial neural network models. Biosystems Engineering 105: 306-315. - doi: 10.1016/j.biosystemseng. 2009.11.010

Falkenmark M (2003). Freshwater as shared between society and ecosystems: from divided approaches to integrated challenges. Philosophical transactions of the Royal Society of London Series B Biological sciences 358: 2037-2049. [online] URL: http://rstb.royalsocietypublishing. org/content/358/1440/2037.short

Farrington P, Bartle GA, Watson GD, Salama RB (1994). Long-term transpiration in two eucalypt species in a native woodland estimated by the heat-pulse technique. Australian Journal of Ecology 19: 17-25. - doi: 10.1111/j.1442-9993.1994. tbo1538.x

Fitzgerald J, Jacobsen JB, Blennow K, Thorsen BJ, Lindner M (2013). Climate change in Euro- pean forests: how to adapt. Policy Brief no 9, European Forest Institute, Joensuu, Finland, pp. 16. [online] URL: http://curis.ku.dk/ws/files/ 99154708/Fitzgerald_et_al_EFI_Policy_Brief.pd $\mathrm{f}$

Garcia-Santos G (2007). An ecohydrological and soils study in a montane cloud forest in the National Park of Garajonay, La Gomera. PhD thesis, Vrije Universiteit, Amsterdam, The Netherlands, pp. 188. [online] URL: http://dare. ubvu.vu.nl/handle/1871/12697

Garcia-Santos G (2011). Transpiration in a subtropical ridge-top cloud forest. Journal of Hydrology 462: 42-52. [online] URL: http://dare. ubvu vu.nl/handle/1871/12697

Gorgens EB, Leite HG, Santos HN, Gleriani JM (2009). Estimação do volume de árvores utilizando redes neurais artificiais [Estimate of tree volume using artificial neural nets]. Revista Árvore 33: 1141-1147. [in Portuguese] - doi: 10.1590/S0100-67622009000600016

Gracia CA, Tello E, Sabaté S, Bellot J (1999). GOTILWA: an integrated model of water dynamics and forest growth. In: "Ecological Studies 137: Ecology of Mediterranean Evergreen Oak Forest" (Rodà F, Retana J, Gracia C, Bellot J eds). Springer Berlin, Heidelberg, Germany, pp. 163-179. - doi: 10.1007/978-3-642-58618-7_12 Haykin S (1994). Neural networks, a comprehensive foundation. Macmillan College Publishing Company, New York, USA, pp. 842.

Hornik K, Stinchcombe M, White H (1989). Multilayer feedforward networks are universal approximators. Neural Networks 2: 359-366. - doi: 10.1016/0893-6080(89)90020-8

Huo Z, Feng S, Kang S, Dai X (2012). Artificial neural network models for reference evapotranspiration in an arid area of northwest China. Journal of Arid Environments 82: 81-90. - doi: 10.1016/j.jaridenv.2012.01.016

Igel C, Hüsken M (2003). Empirical evaluation of the improved Rprop learning algorithms. Neurocomputing 50: 105-123. - doi: 10.1016/So9252312(01)00700-7

IPCC (2007). Summary for policymakers. In: “Climate Change 2007: Impacts, Adaptation and Vulnerability. Contribution of Working Group II to the Fourth Assessment Report of the Intergovernmental Panel on Climate Change" (Parry ML, Canziani OF, Palutikof JP, Van der Linden CE, Hanson CE eds) Cambridge University Press, Cambridge, UK, pp. 7-22.

Jasechko S, Sharp ZD, Gibson JJ, Birks SJ, Yi Y, Fawcett PJ (2013). Terrestrial water fluxes dominated by transpiration. Nature 496: 347-350. - doi: 10.1038/nature11983

Jing-Hua X, Rusli X, Kumta AS (2010). Feedforward neural network trained by BFGS algorithm for modeling plasma etching of silicon carbide. IEEE Transactions on Plasma Science 38: 142-148. - doi: 10.1109/TPS.2009.2037151 Kramer K (2001). Process-based models for scaling up to tree and stand level. In: "Long-Terms effects of climate change on carbon budgets of forests in Europe. " (Kramer K, Mohren GMJ eds). Report no. 194, Alterra, Green World Research, Wageningen, The Netherlands, pp. 6178.

Kramer K, Leinonen I, Bartelink HH, Berbigier $\mathrm{P}$, Borghetti $M$, Bernhofer C, Cienciala E, Dolman AJ, Froer O, Gracia CA, Granier A, Grünwald T,
Hari P, Jans W, Kellomäki S, Loustau D, Magnani F, Markkanen T, Matteucci G, Mohren GMJ, Moors E, Nissinen A, Peltola H, Sabaté S, Sanchez A, Sontag $M$, Valentini $R$, Vesala $T$ (2002). Evaluation of six process-based forest growth models using eddy-covariance measurements of $\mathrm{CO}_{2}$ and $\mathrm{H}_{2} \mathrm{O}$ fluxes at six forest sites in Europe. Global Change Biology 8: 213230. - doi: 10.1046/j.1365-2486.2002.00471.x

Kumar M, Raghuwanshi NS, Singh R, Wallender WW, Pruitt WO (2002). Estimating evapotranspiration using artificial neural network. Journal of Irrigation and Drainage Engineering 128: 224-233. - doi: 10.1061/(ASCE)0733-9437(2002)12 8:4(224)

Kumar M, Raghuwanshi NS, Singh R (2011). Artificial neural networks approach in evapotranspiration modeling: a review. Irrigation Science 29: 11-25. - doi: 10.1007/s00271-010-0230-8

Lagergren F, Lindroth A (2002). Transpiration response to soil moisture in pine and spruce trees in Sweden. Agricultural and Forest Meteorology 112: 67-85. - doi: 10.1016/S0168-1923 (02)00060-6

Lawrence DM, Thornton PE, Oleson KW, Bonan GB (2007). The partitioning of evapotranspiration into transpiration, soil evaporation, and canopy evaporation in a GCM: impacts on landatmosphere interaction. Journal of Hydrometeorology 8: 862-880. - doi: 10.1175/JHM596.1 Leite HG, Silva MLM, Binoti DHB, Fardin L, Takizawa FH (2011). Estimation of inside-bark diameter and heartwood diameter for Tectona grandis Linn. trees using artificial neural networks. European Journal of Forest Research 130: 263-269. - doi: 10.1007/s10342-010-0427-7

Li XY, Yang P, Ren S (2009). Study on transpiration model for fruit tree based on generalized regression neural network. In: Proceedings of the "International Conference of Engineering Computation". Washington (DC, USA) 2-3 May 2009. IEEE Xplore, IEEE, NY, USA, pp. 269-272. doi: 10.1109/ICEC.2009.71

Lindner M, Maroschek M, Netherer S, Kremer A, Barbati A, Garcia-Gonzalo J, Seidl R, Delzon S, Corona P, Kolström M, Lexer MJ, Marchetti M (2010). Climate change impacts, adaptive capacity, and vulnerability of European forest ecosystems. Forest Ecology and Management 259: 698-709. - doi: 10.1016/j.foreco.2009.09.023 Liu X, Kang S, Li F (2009). Simulation of artificial neural network model for trunk sap flow of Pyrus pyrifolia and its compartion with multiplelinear regression. Agricultural Water Management 96: 939-945. - doi: 10.1016/j.agwat.2009. 01.003

Mackay SL, Arain MA, Khomik M, Brodeur JJ, Shumacher J, Hartmann H, Peichl M (2012). The impact of induced drought on transpiration and growth in a temperate pine plantation forest. Hydrological Process 26: 1779-1791. - doi: 10.1002/hyp.9315

Maier HR, Dandy GC (2000). Neural networks for the prediction and forecasting of water resources variables: a review of modelling issues and applications. Environmental Modelling and Software 15: 101-124. - doi: 10.1016/S1364-8152 (99)00007-9

Meijun Y, Peiling Y, Shumei R, Yuanpei L, Tingwu $X$ (2007). A backward propagation neural network for predicting daily transpiration of pop- 
lar. New Zealand Journal of Agricultural Research 50: 1277-1284. - doi: 10.1080/002882307 09510413

Molina AJ, Del Campo A (2012). The effects of experimental thinning on throughfall and stemflow: a contribution towards hydrology-oriented silviculture in Aleppo pine plantations. Forest Ecology and Management 269: 206-213. doi: 10.1016/j.foreco.2011.12.037

Morales P, Sykes M, Prentice C, Smith P, Smith B, Bugmanns $H$, Zierls $B$, Friedlingstein $P$, Viovy $N$, Sabaté S, Sánchez A, Pla E, Gracia CA, Sitch S, Arneth A, Ogee J (2005). Comparing and evaluating process-based ecosystem model predictions of carbon and water fluxes in major European forest biomes. Global Change Biology 11: 2211-2233. - doi: 10.1111/j.1365-2486.2005.01036.x Nawi NM, Ransing MR, Ransing RS (2006). An improved learning algorithm based on the Broyden-Fletcher-Goldfarb-Shanno (BFGS) method for back propagation neural networks. In: Proceedings of the " 6 th International Conference on Intelligent Systems Design and Applications". Jinan (Shandong, China) 16-18 Oct 2006. IEEE Xplore, IEEE, NY, USA, pp. 152-157. - doi: 10.1109/ISDA.2006. 95

Özçelik R, Diamantopoulou M, Brooks J, Wiant H (2010). Estimating tree bole volume using artificial neural network models for four species in Turkey. Journal of Environmental Management 91: 742-753. - doi: 10.1016/j.jenvman.2009.10.002 Özçelik R, Diamantopoulou M, Brooks J (2014). The use of tree crown variables in over-bark diameter and volume prediction models. iForest 7: 132-139. - doi: 10.3832/iforo878-007

Özesmi SL, Tan CO, Özesmi U (2006). Methodological issues in building, training, and testing artificial neural networks in ecological applications. Ecological Modelling 195: 83-93. - doi: 10.1016/j.ecolmodel.2005.11.012

Riedmiller M, Braun H (1993). A direct adaptive method for faster backpropagation learning: the RPROP algorithm. In: Proceedings of the "IEEE - International Conference on Neural Networks". San Francisco (CA, USA) 29 Mar - 01 Apr 1993. IEEE, New York, USA, pp. 586-591. doi: 10.1109/ICNN.1993.298623

Rinn F (2011). Tsap-Win software. Rinntech, Heidelberg, Germany, pp. 91.

Schiller G, Cohen Y (1998). Water balance of
Pinus halepensis Mill. afforestation in an arid region. Forest Ecology and Management 105: 121-128. - doi: 10.1016/S0378-1127(97)00283-1

Shirgure PS (2013). Evaporation modeling with artificial neural network: a review. Scientific Journal of Review 2: 73-84.

Shirgure PS, Rajput GS (2011). Evaporation modeling with neural networks: a research review. International Journal of Research and Reviews in Software Intelligent Computing 1: 37.

Silva MLM, Binoti DHB, Gleriani JM, Leite HC (2009). Ajuste do modelo de Schumacher e Hall e aplicação de redes neurais artificiais para estimar volume de árvores de eucalipto [Adjustment of the Schumacher and Hall model and application of artificial neural networks to estimate volume of eucalypt trees]. Revista Árvore 33: 1133-1139. [in Portuguese] - doi: 10.1590/So10 0-67622009000600015

Smith JT (2006). Neural network verification. In: "Methods and Procedures for the verification and validation of Artificial Neural Networks" (Taylor BJ ed). Institute for Scientific Research, Fairmont, USA, pp. 109-160. - doi: 10.1007/0-38729485-6 6

Taylor BJ, Smith JT (2006). Validation of neural networks via taxonomic evaluation. In: "Methods and Procedures for the verification and validation of Artificial Neural Networks" (Taylor BJ ed). Institute for Scientific Research, Fairmont, USA, pp. 51-95. - doi: 10.1007/0-387-2948 5-6_4

Ungar ED, Rotenberg E, Raz-Yaseef N, Cohen S, Yakir D, Schiller G (2013). Transpiration and annual water balance of Aleppo pine in a semiarid region: implications for forest management. Forest Ecology and Management 298: 39-51. doi: 10.1016/j.foreco.2013.03.003

Van Oijen M, Rougier J, Smith R (2005). Bayesian calibration of process-based forest models: bridging the gap between models and data. Tree Physiology 25: 915-927. - doi: 10.1093/tree phys/25.7.915

Vargas-Amelin E, Pindado P (2013). The challenge of climate change in Spain: water resources, agriculture and land. Journal of Hydrology 518: 243-249. - doi: 10.1016/j.jhydrol.2013.11.035

Vojislav K (2001). Learning and soft computing: support vector machines, neural networks, and fuzzy logic models. The MIT press, Boston, MA,
USA, pp. 541. [online] URL: http://books. google.com/books?id=W5SAhUqBVYoC

Vrugt JA, Bouten W, Dekker SC, Musters AD (2002). Transpiration dynamics of an Austrian Pine stand and its forest floor: identifying controlling conditions using artificial neural networks. Advances of Water Resources 25: 293303. - doi: 10.1016/S0309-1708(01)00061-6

Whitley R, Medlyn B, Zeppel M, Macinnis-Ng C, Eamus D (2009). Comparing the Penman-Monteith equation and a modified Jarvis-Stewart model with an artificial neural network to estimate stand-scale transpiration and canopy conductance. Journal of Hydrology 373: 256-266. doi: 10.1016/j.jhydrol.2009.04.036

Whitley R, Taylor D, Macinnis-Ng C, Zeppel M, Yunusa I, O'Grady A, Froend R, Medlyn B, Eamus $D$ (2012). Developing an empirical model of canopy water flux describing the common response of transpiration to solar radiation and VPD across five contrasting woodlands and forests. Hydrological Processes 27: 1133-1146. doi: 10.1002/hyp.9280

Yu S, Jia-Yin Z (2012). The application of artificial neural network model in estimation of single tree volume growth. In: Proceedings of the " 2 nd International Conference on Remote Sensing Environment and Transportation Engineering". Najing (China) 1-3 Jun 2012. IEEE Xplore, NJ, USA, pp. 1-6. - doi: 10.1109/RSETE.2012.6260764 Zee $F$ (2001a). Modelling of assimilation and transpiration processes using artificial neural networks. In: Proceedings of the " $28^{\text {th }}$ Annual Conference of the Plant Growth Regulation Society of America". Miami Beach (FL, USA) 1-5 Jul 2001. Beacon eSpace, Caltech, Pasadena, CA, USA, pp. 1. [online] URL: http://hdl.handle. net/2014/12794

Zee F (2001b). Modeling of assimilation and transpiration in soybean plants using artificial neural networks. In: Proceedings of the "Bioastronautics Investigators Workshop". Galveston (TX, USA) 17-19 Jan 2001. USDRA, Houston, TX, USA, pp. 46. [online] URL: http://www.dsls. usra edu/meetings/bio2001/pdf/046.pdf

Zhang GB, Patuwo E, Hu MY (1998). Forecasting with artificial neural networks: the state of the art. International Journal of Forecast 14: 35-62. doi: 10.1016/S0169-2070(97)00044-7 